\title{
LA ECOLOGÍA PROFUNDA EN RESPUESTA A LA CRISIS AMBIENTAL: PENSANDO EL MEDIO AMBIENTE DESDE AMÉRICA LATINA
}

\author{
Dra. Soledad Escalante Beltrán \\ Universidad Antonio Ruiz de Montoya
}

\begin{abstract}
RESUMEN
Este artículo explora las ideas de Arne Naess sobre el cambio de paradigma entre una ética antropocéntrica hacia una ética biocéntrica en el marco de una ecología profunda que contrasta con una superficial. Estudiamos algunos casos en América Latina para establecer el vínculo entre el colonialismo y la depredación ecológica, así como la deshumanización de lo indígena. Desde el punto de vista de la de-colonización, también es importante considerar la teoría crítica del pensamiento post-hegeliano, reflejada en los pensadores de la Escuela de Frankfurt. Podemos considerar que la crítica a la modernidad encaja completamente en la mentalidad del imperialismo y la colonización, y esto tiene un impacto directo en la relación entre la ecología y las sociedades que han sido despojadas de las formas de vida antiguas para ser reemplazadas por la cultura industrial de países del tercer mundo.
\end{abstract}

\section{PALABRAS CLAVE}

Ecología, colonialismo, teoría crítica, ecología profunda, decolonialismo

\begin{abstract}
This article explores the idea of Arne Naess about the paradigm shift between an anthropocentric ethics towards a biocentric ethics in the frame of a Deep ecology that contrasts with a shallow one. We study some cases in Latinamerica to establish the link between colonialism and ecology depredation, as well as the de-humanization of the indigenous. In the way of a de-colonization perspective, it is also important to consider the Critical Theory of post-hegelian thought, reflected in thinkers of the Frankfurt School. We can consider that the critic to modernity fits entirely into the mentality of imperialism and colonization, and this has a direct impact into the relation between ecology and societies that have been stripped of ancient ways of life to be replaced with the industrial culture of third world countries.
\end{abstract}

\section{KEY WORDS}

Ecology, Colonialism, Critical Theory, Deep Ecology, Decolonialism 


\section{Introducción}

Este artículo busca explorar el contexto sudamericano para identificar elementos con los que podamos encontrar asociaciones en lo que refiere a la crisis ambiental. Examinaremos la relación fundamental entre la teoría crítica y la teoría de la ecología profunda como una alternativa para interpretar el estado de la crisis ambiental en Latinoamérica. Así, revisar el concepto de colonialismo será crucial.

Buscaremos elaborar el marco de un pensamiento colonialista, como aquel que ha prefigurado el desarrollo de América Latina, al tiempo que estableceremos las características de tal estructura social. Para estudiar el caso latinoamericano, atenderemos a dos casos de voces indígenas que lograron sobrevivir en la historia: Guamán Poma de Ayala y el Inca Garcilaso de la Vega, ambos, quienes protestan en contra de un régimen injusto de explotación y depredación natural. Hay dos puntos que debemos rescatar de tales críticas y es el abuso de la condición humana del indio y la inconsciencia con que se administran los recursos y espacios medio ambientales.

A continuación, vincularemos la teoría crítica con el pensamiento de-colonialista en el marco de un esquema moderno antropocéntrico. Ello supone elaborar los lazos que tiene el colonialismo con el pensamiento político moderno, el cual percibe a la razón instrumental como el eje de su propuesta. La crítica a la razón instrumental es una que puede ponerse en paralelo a la crítica al colonialismo, no solo porque la presupone, sino, especialmente, si consideramos el punto crucial en cuyas nociones convergen: una crisis ambiental que escapa de nuestras manos y previsiones.

Finalmente, haremos una revisión del concepto de una ecología profunda como respuesta al colonialismo ambiental en América Latina. Ello supone luchar contra cierta estructura que ha favorecido diversas inequidades y atropellos culturales. En ese sentido, buscamos entablar una conexión entre la ecología profunda y la tendencia de-colonialista como resultado de la preocupación por el deterioro ambiental, pero en donde se reconoce al mismo tiempo una situación social que, asimismo, se ve envuelta en una crisis.

\section{Una perspectiva de América Latina desde Garcilaso y Guamán Poma}

La historia de América se encuentra escindida por un eje histórico que supone un antes y un después. Existe una polaridad social que, en algunos elementos, parece haberse mantenido hasta el día de hoy. Nos referimos a la irrupción del pasado sepultado por la conquista. Veremos que las relaciones que podemos formular entre estas instancias y el medio ambiente pueden cargar un valor muy significativo.

Podemos incurrir en una idealización, pero, por lo general, se ha configurado una idea respecto a la relación de los pueblos originarios con la naturaleza. Tengamos en cuenta que las culturas pre incas dejaron como legado la evidencia de una relación sostenible y estable con la naturaleza. Por otro lado, con la conquista experimentamos progresivamente hasta el presente un afán de depredación en un arrebato de explotación desmedida de los recursos, lo cual, viene de la mano con una imposición de la mentalidad capitalista y la práctica consumista. Al mismo tiempo, supone de paralelamente el adoctrinamiento de una religión que censura intensamente otros pensamientos. Todo ello deriva en una visión justificadamente negativa del "invasor" por cuanto 
destructor de un mundo, de su cosmovisióny, especialmente, de las relaciones saludables con una naturaleza que se interpreta de modo muy distinto que instrumentalmente.

Bautista (2014) nos invita a contemplar la diferencia entre un pensar "para" y un pensar "desde". Cuando pensamos "para", incurrimos en un objetivismo y supone un modelo clásico de la razón instrumental que defienden los modernos. El pensar "desde" nos compele a un des-centralismo con un carácter más cercano a la fenomenología, en el sentido en que suspendemos los datos colaterales de lo contemplado, para limitarnos a lo dado, respetando aquello que tiene que decirnos. De lo contrario, un pensar "para" establece la dialéctica de sujeto-objeto y ello puede suponer caer en el antropocentrismo, además de la objetivación reificadora de entidades como personas o pueblos.

En este sentido, la naturaleza misma ha sido cosificada, del mismo modo que el "otro", en cuanto indígena, ha sido referido como una bestia sin alma, sin razón y cuya causa requiere de un paternalismo aculturador. Se ha eliminado una subjetividad comunitaria y de ahí la necesidad de un pensar "desde" una visión casi perdida en la historia.

Para pensar "desde" un lugar de la olvidada Latinoamérica, podemos atender a dos personajes como Garcilaso de la Vega y Guamán Poma de Ayala. Ellos nos ofrecen un antecedente tangencial de lo que hoy se establece como el ideal del "buen vivir" en las marginalidades occidentales.

Mazzotti (2018) rastrea un punto de no retorno en la historia medioambiental en el momento del despliegue de la minería colonial (sin mencionar la explotación esclavizadora). Ello supone un quiebre de la relación que venía ejerciéndose ancestralmente con la naturaleza. Para ello, Mazzotti desarrolla una relectura del Inca Garcilaso de la Vega, quien en sus Comentarios Reales expone de qué modo la imposición colonial subvertía las ideas de prioridades culturales: "Advertían ya desde el siglo XVII de los peligros de la excesiva explotación minera y la ruptura de una relación armoniosa y auto-sostenible con la naturaleza. Lo hace en comparación con la política de los incas sobre el uso de metales preciosos, que tenían una finalidad principalmente ritual" (Mazzottu, 2018, p.82).

De acuerdo a lo dicho antes, podemos hacer un paralelo entre lo criticado en los Comentarios Reales con la mencionada lógica colonialista que deriva del triunfo de la moderna razón instrumental, cuyas consecuencias han terminado doblegando el equilibrio medioambiental. En el horizonte del caso del Inca Garcilaso, y en paralelo a lo referido previamente por Bautista, Mazzotti (2018) nos refiere que:

Una de las lecciones que pueden extraerse de los Comentarios reales es el dar cuenta de una relación particular que tenían la población indígena y su estado incaico con lo que nosotros entendemos como naturaleza. [...]. Se trataba de establecer una relación de sujeto a sujeto con el mundo natural, no de sujeto a objeto como plantea la racionalidad occidental moderna. Este poder ser en el mundo, sin necesidad de poder poseer, parece plantear en la visión garcilasiana una ética que genera a su vez una relación particular entre el estado y súbditos (Mazzotti, 2018, p. 83). 
En la misma línea, Carlos A. Rossi (2018) revisa las crónicas de Guamán Poma de Ayala y el Inca Garcilaso para concluir que de "estas representaciones emergen visiones del mundo en las que confluyen el pasado y el presente, y las culturas incaica y española como dos modulaciones en conflicto." (Rossi, 2018, p. 27).

La imposición de una lógica colonial puede observarse del mismo modo en el caso de Guamán Poma de Ayala, defensor de los derechos indígenas y quien reclamaba entonces un trato justo ante la explotación insular. Tal sometimiento y modo de relación entre individuos y con la naturaleza, de carácter cruento, iba en contra de sus ideales incas, a quien no podemos idealizar como pacíficos, pero cuando menos, se puede constatar que lejos de explotar los recursos, tenían lo natural como algo que no defraudaban con la instrumentalización antropocéntrica de esta, por el contrario, se buscaba una armonía horizontal, antes que ocupar la punta de alguna pirámide teoontológica.

Beuchot (1993) en un estudio sobre Bartolomé de las Casas, señala, respecto a la condición del indio en tiempos coloniales, de acuerdo a los reclamos que realiza Guaman Poma, que:

Toda esa labor que realizó en la defensa de los derechos de los indios y de los españoles en el momento de conquista, era en realidad una labor dedicada a la teorización y defensa práctica de los derechos humanos. Del lado de los indios, defiende su racionalidad, su libertad, su derecho a gobernarse por sí mismos, su derecho a no aceptar la religión cristiana; en ello defendía derechos humanos muy importantes. Lo mismo hacía cuando, del lado de los españoles, defendía el derecho a establecerse en otras tierras, a comunicar a los indios la cultura europea y señaladamente a predicarles el evangelio. Como ponía la condición de que no se lesionaran los derechos de los indios ni el bien común de esas tierras, y como esos derechos y ese bien común fueron ultrajados, veía en ello residir la injusticia de la colonización. Pero en todo momento trataba de salvaguardar los derechos humanos de ambos protagonistas $\mathrm{y}$, por ende, los del hombre mismo, fuese quien fuese. (Beuchot, 1993, p. 8).

Lejos de ser irracionales, los habitantes ancestrales de los pueblos originarios de toda América han demostrado una tendencia al ideal de convivir con la naturaleza. Desde su mentalidad, era insensato preferir la devastación de un mundo por encima de la abusiva producción para una corona ajena. Desde el otro punto de vista, el hogar devastado era de otros y, acaso de ahí, la indiferencia ambiental y cultural.

En virtud de la imposición de un método nuevo de intercambio y comercio, Garcilaso nos dice que para los Incas los metales eran estimados por su resplandor, brillo y hermosura; de modo ornamental y suntuario. La mentalidad de acumular recursos, los valores de cambio y no de uso, así como los medios instrumentales para hacerse con dichos bienes, suponen, en conjunto, la transformación de una sociedad ambientalista a una esclavizada y de cultura impuesta.

Al atender a los reclamos de Garcilaso y Guamán Poma, podemos dar cuenta de un hecho histórico que ha quebrado la relación de uno con el otro. El mismo contexto ha supuesto una transformación en la mentalidad y aproximación hacia un más lejano otro: la naturaleza. Tanto lo indígena como lo natural parecen haber sido pasados por alto, de acuerdo a estos testimonios. El respaldo que encontraríamos en otras fuentes, bien podría enriquecer la postura de una identidad fragmentada en su construcción histórica en el contexto del colonialismo sudamericano. Baste 
atender al fenómeno de resistencia social-religiosa del Taqui-Onkoy, que anticipaba a modo de rumor de sismo la revolución en Tinta y con ello la fuerza independentista, ahí en donde el yugo apretaba con más fuerza.

En miras de vincular pasado y presente, revisemos la idea de un pachamamismo biocéntrico, de acuerdo a una interpretación contemporánea, que sigue a un artículo de Martinez y Porcelli. Las autoras de Una nueva visión del mundo: la ecología profunda y su incipiente recepción en el derecho nacional e internacional (primera parte) (2017), sostienen que el desarrollo de la industria y el consecuente crecimiento económico ligado a las tecnologías modernas, han implicado un aumento considerable en el consumo de bienes a expensas de la depredación de recursos naturales.

De acuerdo a lo denunciado por las voces del pasado, se reclama que parecieran haberse dejado de lado los derechos del indio y de la madre tierra. En el artículo referido se plantea una revisión de teorías que afirman la idea de una naturaleza como sujeto de derechos. Se revisa la idea de un biocentrismo como alternativa a nuestro usual antropocentrismo. En esa línea, el estudio hace referencia a una teoría ancestral de la consideración de nuestra naturaleza. Nos referimos a la idea quechua de Madre Tierra o Pachamama.

De acuerdo a cómo lo exponen Martinez y Porcelli, la teoría de la Pachamama se basa en una espiritualidad de la tierra cuya fuente se encuentra en el imaginario colectivo de la cosmovisión de pueblos ancestrales nativos. En particular, se refieren a los usuarios del antiguo quechua. Las autoras (2017) nos invitan a considerar algunos términos fundamentales en miras de definir la "buena vida":

Sumak significa lo ideal, lo hermoso, lo bueno, la realización; y kawsay es la vida, en referencia a una vida digna, en armonía y equilibrio con el universo y el ser humano. Es una expresión quechua que significa buen vivir o pleno vivir. Para el filósofo andino Javier Lajo Lazo, el Sumak kawsay puede ser entendido como el pensar bien, sentir bien para hacer bien, con el objetivo de conseguir la armonía con la comunidad, la familia, la naturaleza y el cosmos. No se trata del tradicional bien común limitado a los humanos, sino del bien de todo lo viviente, incluyendo por supuesto a los humanos, entre los que exige complementariedad y equilibrio, no siendo alcanzable individualmente. El Sumak kawsay es un sistema de vida en el que la Pachamama adquiere no solamente la categoría de sujeto de derechos, sino también de connotación política, religiosa y mágica. Sistema de vida, entendido como el conjunto de principios, normas o reglas que establecen un modelo económico, social y político de una sociedad. Por ello, en primer lugar, exige una forma de organización social básica que es la comunidad; sin embargo, no significa que termina en la organización social o reunión de personas, porque la comunidad, al igual que el ser humano, es parte complementaria del todo. Este "modelo" depende de cuatro principios básicos que son parte de la filosofía andina: relacionalidad, correspondencia, complementariedad y reciprocidad. (Martinez \& Porcelli, 2017, p. 433).

La concepción de Pachamama como posibilidad de relación sostenible con el medio ambiente es desarrollada también por Gudynas (2017), Hidalgo-Capitán y Cubillo-Guevara (2017), entre otros. 
Debemos preguntarnos qué mentalidad condujo a esa ruptura en donde lo indígena y la naturaleza han quedado relegadas a instrumentos y objetos descartables. La crónica crisis de identidad latinoamericana encuentra su punto más agudo cuando se cruza con una crisis ambiental global, que parece responder a la misma lógica problemática de explotación. Con crisis de identidad no queremos decir que el americano no sepa quién es, sino que tiene retos complejos en su identidad en lo que refiere a las prioridades y establecimiento de leyes adecuadas en relación a una posición económica adecuada para discutir los términos de intercambio global, así como en el criterio de sus prioridades morales.

Las voces de Garcilaso y Guamán Poma denuncian la ruptura entre pachamamismo y colonialismo, en donde tenemos dos grandes afectados: el estado de lo indígena y la conservación de los ambientes naturales. Ambos, vistos como elementos sujetos a dominación. Para profundizar en las raíces de la crisis ambiental, podemos adentrarnos en la lógica de un colonialismo que tiene como soporte una cuestionable razón instrumental.

\section{La crisis del medio ambiente como triunfo del colonialismo}

El caso de América Latina retratado por los cronistas indígenas y el rescate del panorama del pachamamismo reclama una ruptura entre un paradigma pre-occidental y otro moderno. El pensamiento y la práctica colonial suponen, entre otras cosas, el sometimiento de lo indígena y lo natural. Ambos se ven amenazados en el imperio de tales prácticas instrumentalizadoras.

Bautista (2014) retrata de modo fidedigno el modo en que lo no occidental ha sido invisibilizado por una concepción objetivante y cosificadora. Cuestiona la idea de un pensar exclusivamente occidental como la imposibilidad de reconocimiento de otros pensamientos. Por el contrario, sostiene lo siguiente:

Si esto fuese así [que el pensar sea en esencia occidental], toda cultura o civilización no occidentales no serían originariamente filosóficas, esto es, la pregunta por lo que la filosofía sea, o por lo que el pensar sea, ya no podría conducirnos a nuestros propios orígenes, sino inevitablemente a los orígenes de Occidente, que serían griegos. Por ello, en general, todo aquel que estudia filosofía, no solo estudia a los griegos, sino a los occidentales. Y así, los no occidentales pasan y pasamos a segundo plano para el preguntar acerca de lo que sea el pensar o el conocer en general. (Bautista, 2014, p.79).

Podríamos decir que, si queremos rastrear el problema esencial de la crisis ambiental, debemos considerar que el hombre ha incurrido culturalmente en un discurso liderado por los ideales modernos y la lógica colonialista, la cual hace suyos los elementos de instrumentalización en pos del dominio hegemónico. Los elementos que criticaban Garcilaso y Guamán Poma no son distintos.

En este sentido, para presentar a Latinoamérica en el horizonte de la crisis ambiental, hace falta confrontar las consideraciones de-colonialistas, las cuales ofrecen eco a voces marginadas y cuya importancia ha sido minimizada por la matriz social que busca homogenizar de manera totalizante. Con esta lectura coincide Mignolo (2010), quien refiere que el colonialismo es un 
aspecto constitutivo de las aspiraciones modernas: "en el sentido de que no puede haber modernidad sin colonialidad, entonces, la retórica de la modernidad y la lógica de la colonialidad son también dos caras de la misma moneda.” (Mignolo, 2010, p. 46)

Dicha relación puede explicarse en el fundamento que posee el afán moderno de una razón instrumental y el control de la naturaleza mediante el entendimiento de los fenómenos naturales traducibles en leyes estables y determinadas que permitan la predicción. Tal elemento de conveniencia humana en desmedro de lo otro es el antropocentrismo; para el pensamiento moderno que influye en la lógica colonialista, los seres humanos, (especialmente, unos más humanos que otros), son el centro para redefinir un nuevo paradigma de relación ocupacional con la naturaleza.

Del mismo modo, el antropocentrismo moderno se rige por una dialéctica de sujeto-objeto en un horizonte de racionalismo instrumental. En ese contexto es que vemos a algunos grupos humanos y a la naturaleza cosificados y objetivados para un potencial servicio o explotación. Ello, siguiendo al título del libro de Broswimmer (2005), supone un ecocidio, ya que la mentalidad occidental se pretende universal y compele a todos a un estilo de vida consumista que favorece la depredación natural, condena a los marginados y desfavorecidos de todo tipo; desde individuos, grupos, sistemas humanos y naturales hasta la aniquilación de nuestro ambiente.

Debemos aclarar que, si bien históricamente el colonialismo significó estos y otros problemas sociales y políticos, no por eso debemos desentendernos de los mismos en la actualidad, por el contrario, debemos reconocer cuan influenciados nos encontramos por tal estructura que no ha terminado de superarse. Las cadenas ominosas del racismo, clasismo, sexismo, entre otras, no son extrañas a nuestras sociedades.

Horkheimer ubica, en este sentido, un problema crítico que se mantiene vigente por parte del influjo del pensamiento moderno. El dominio de la naturaleza y el trato instrumental son algo que se propaga al ámbito del ser humano. Ello nos lleva a una lucha por dominar la alteridad, generándose así una relación dual entre opresor y oprimido. El sometimiento se da en diversas instancias, como la naturaleza, la mujer, el tercer mundo, el no-occidental, entre otros; todos invisibilizados y convertidos en sujetos-objetos.

Un rasgo conocido de la concepción moderna es la prioridad de la razón instrumental y su consiguiente aparato de herramientas técnicas; Horkheimer (1969) refiere lo siguiente sobre la dualidad de individuo y naturaleza:

Como resultado final del proceso tenemos, por un lado, el yo, el ego abstracto, vaciado de toda substancia salvo de su intento por convertir todo lo que existe en el cielo y sobre la tierra en medio para su preservación y, por otro, una naturaleza huera, degradada a mero material, mera substancia que debe ser dominada sin otra finalidad que la del dominio (Horkheimer, 1969, p.107).

Podemos notar de qué modo la humanidad moderna ha figurado un camino sin salida, en cuanto reconoce la necesidad material de sobrevivir, pero, al mismo tiempo, cosifica el planeta que es presupuesto para su vivirantes que pueda darse cualquier discusión acerca del buen vivir. Las 
conductas anti-ecológicas atentan en contra de la condición de posibilidad misma para la vida en nuestro planeta, incluida la nuestra.

El dominio, de acuerdo a Horkheimer, no tiene límites, pues es esencial para la visión colonialista moderna. Es propio de una sociedad histórica y dinámica que ha reflejado prácticas depredativas y explotadoras. El fundamento de tal concepción es el principio de razón instrumental utilitaria. En ese sentido, el dominio que busca la razón instrumental no acaba en lo natural, sino que afrenta a la misma humanidad. Esto es evidente al atender las palabras de Horkheimer (2007), quien refiere que: "El ser humano, en su proceso de emancipación, divide el destino del mundo que le resta. El dominio sobre la naturaleza abarca el dominio sobre el ser humano" (Horkheimer, 2007, p.110).

Con esta interpretación se encuentran de acuerdo Mayer-Tasch y otros al referir en Natur denken (2019) lo siguiente:

En una razón instrumentalizada, la naturaleza ya no entra en discusión al ser reducida ésta a mero material. Horkheimer analiza los trasfondos sociales, económicos e históricos que explican por qué el dominio progresivamente perfeccionado sobre la naturaleza se torna destructiva hacia el ser humano, al transformarse esta en una revuelta de la naturaleza hacia el mismo.

El caso de América Latina parece ser provechoso para ver cómo convergen la opresión colonial y la crisis ambiental. Siguiendo a Mignolo (2010), vivimos en una matriz colonial, que se extiende sin límites por nuestro modo de entender el mundo, por la manera de administrar nuestros recursos y por las relaciones sociales que entablamos culturalmente.

La segregación colonialista que ha perdurado en los usos socio-económicos de América Latina coincide plenamente con la negligencia de considerar a la naturaleza como objeto de derecho. Gudynas (2017) refiere un caso inusual al señalar a la constitución ecuatoriana del 2008 como la que mayor impacto ha tenido en el actuar político social, pues les reconoce a los seres vivos, incluidos los inanimados, ser sujetos de derecho. Aún más, promueve el impulso de un mantenimiento y desarrollo natural contrapuesto a los intereses antropocéntricos. Al margen de dicha sorpresiva anomalía, por lo general, la negligencia a la que hacemos referencia, supone la normalización de una instrumentalización y cosificación de lo natural para usarlo de alfombra en las pisoteadas de un capitalismo depredador.

No podemos negar, aunque se haya sostenido, que la crisis sea real. Es incuestionable que los índices de polución y deterioro ambiental, además de la extinción de diversas especies animales y vegetales, responden a indicadores muy altos. En los últimos años, luego del despliegue industrial, somos testigos de niveles abominables de aniquilación planetaria. Si ser negligente en reconocer esto es peligroso, pensemos que, además, debemos indicar que la humanidad es responsable de llevar a tal estado los niveles de supuesto "desarrollo" y no tenerlo en cuenta jugaría en contra nuestra, puesto que la inconsciencia ambiental sepulta nuestro destino.

De este modo, considerando que las raíces del colonialismo coinciden con la misma mentalidad que propicia una crisis global del medio ambiente, sopesemos la idea de una transformación del eje antropocéntrico por un núcleo distinto. Esto no puede partir sino de reconocer a la crisis 
ambiental como triunfo de un pensamiento colonialista que se soporta en una mentalidad que privilegia la razón instrumental en detrimento de lo humano y natural.

\section{Una ecología profunda como propuesta de-colonialista}

Los esfuerzos por atender la crisis global del medio ambiente no son pocos, pero en algunas ocasiones se los ha acusado de superficiales. El impacto es tan grave que las medidas que tomamos son insuficientes para revertir la situación. Decir que hemos tomado consciencia sería un exceso, puesto que las prácticas no se traducen en un cambio estructural de nuestras costumbres medioambientales.

Se han firmado tratados, acuerdos, convenios y demás que buscan refrenar la contaminación y agotamiento de recursos no renovables. La sociedad, sin embargo, política y culturalmente, en el panorama de sus prioridades, prefiere favorecer a pocas corporaciones e intereses antes que a los de una relación equilibrada con lo natural. Algunos ecologistas, sean del campo científico o social, han señalado que las medidas tomadas en proporción con la crisis suponen que no hemos ido con suficiente profundidad a la gravedad del problema.

Los movimientos verdes, los congresos internacionales y los intentos de concientizar sobre el medio ambiente quedan en la superficie. A partir de una reunión de las Naciones Unidas, Arne Naess (1973) sostuvo que podemos identificar un trato derivado de una versión clásica de la ciencia, como una ecología superficial, contrapuesta, a una necesaria ecología profunda.

En la postura de una ecología superficial, la naturaleza se ve cosificada para cumplir con las perspectivas positivistas de objetivación y cuantificación. Dicha fragmentación supone una comprensión reduccionista que nubla el origen del problema medioambiental integralmente. Tal visión representa, además, un ejemplo típico de lo que defiende la modernidad que antepone la razón instrumental frente a lo otro.

El problema fundamental de una ecología imprudente supone que no cuestionemos los pilares del pensamiento occidental que estructuralmente sostienen a la razón instrumental como el arma de un totalitarismo utilitarista, al tiempo que se pone a lo "humano", como centro de dicha lógica y en la práctica, se traduce en un consumismo desmedido. Decir "lo humano" puede ser excesivo, considerando que realmente beneficia a sectores limitados y no realmente a lo humano en sí mismo. Existen serios problemas con la postura que una ecología superficial defiende.

Al ser la naturaleza un objeto más de sometimiento, el hombre cae en la negligencia de exterminar el planeta, sin pensar en este cómo su condición de posibilidad. Sin mundo, no hay vida. La humanidad proporcional y relativamente es infinitesimal en comparación con las edades. Empujar al medio ambiente a límites comparables solo con el de las extinciones masivas nos debe hacer reflexionar sobre cómo funcionan de fondo nuestras culturas y sociedades.

La ecología superficial apenas toca la puerta a los problemas del colonialismo anti-ecológico. Por el contrario, una ecología profunda se basa en una cosmovisión que tiene a la vida natural como centro de su despliegue y, de este modo, supone una posición polarmente opuesta. El biocentrismo entiende lo insostenible que puede llegar a ser un régimen colonialista aplicado a lo natural, por 
ello, busca que se propague una estimulación de comportamientos críticos que fomenten en el individuo un activismo lúcido.

Las soluciones al problema de la crisis ambiental no pueden partir de ámbitos de la ciencia o tecnología, mucho menos del mercado y la producción para el consumo masivo. De acuerdo a Naess (1987), el cambio de una ecología profunda debe provenir de procesos o actos de autorrealización.

Por ello, la postura de una ecología profunda supone una interpelación al modo en que dirigimos moralmente nuestras vidas. Para tal fin, es fundamental el papel de un pensamiento crítico capaz de de-construir nuestras costumbres. En este sentido, se fomenta una transformación de nuestro estilo de vida.

Naess (2001) propone una distinción que es importante tener en cuenta. Nos señala que existe una diferencia substancial entre la ecología, la ecofilosofía y la ecosofía. Podemos definir a la primera como una ciencia interdisciplinar cuyo objeto de estudio son las condiciones y naturaleza de un sistema y las relaciones entre los organismos que alberga. El problema de la ecología, de acuerdo a Naess, supone que, en cuanto disciplina científica, no posee un esquema que ofrezca una deconstrucción de los preceptos políticos, sociales y culturales del antropocentrismo. Derivado de ello, se puede constatar que no hay soluciones eficaces en contra de la crisis medio ambiental.

Como alternativa, la filosofía ha desarrollado aspectos del problema de donde podemos ver surgir la llamada ecofilosofía, la cual cuestiona el lugar y papel del ser humano en el ámbito natural y los límites que le corresponden. En un sentido práctico, le ecofilosofía parece carecer de cierto activismo social y de repercusión teórica en la realidad. Para un cambio verdadero, hace falta ir más profundidad. En el plano moral, la ecofilosofía carece de un norte ético propio, pareciera articularse reactivamente en oposición a la crisis ambiental, pero no de acuerdo a un núcleo propio.

La ecosofía, finalmente, propone cambiar de eje en las prácticas económicas y sociales. Se inspira en el concepto de "ecosfera" (Naess, 2001) y tiene por objetivo desarrollar una perspectiva individual y social que pueda comprehender la coexistencia de distintas formas de vida, además de la división interna dentro de la vida humana, es decir, una tolerancia intercultural que empata con el decolonialismo. La ecosofía sostiene la esencial necesidad de ejercer un giro hacia el biocentrismo, renegando de los horrores del antropocentrismo.

A partir de una ecología profunda, se promueve una relación renovada entre la naturaleza y el sujeto humano que parte de una matriz que debe transformar nuestros modelos de organización y producción social por una estructura que respete la diversidad cultural y ecológica, es decir, por el cumplimiento de lo sostenido por el de-colonialismo. En este horizonte se plantea el surgimiento de un sujeto ecológico, apropiado de los fundamentos ontológicos y epistemológicos de la ecología profunda de Naess.

La idea de un sujeto ecológico no es ninguna primicia humana puesto que podemos ver nociones que orbitan su concepto en diferentes casos históricos. Una mentalidad pre-moderna podría sostener, como lo hace el pachamamismo, que todos los seres se interrelacionan y forman una unidad equilibrada y armónica en el cosmos. Podríamos referir tal postura como una suerte de monismo, por cuanto se pretende que hombre, cosmos, naturaleza y orden sean uno solo, 
integralmente. Podemos en la misma línea invocar el panteísmo spinoziano con el deus sive natura, "Dios o naturaleza". Del mismo modo, podríamos asociarlo a tradiciones orientales, tales como el taoísmo naturalista o el budismo. La mística occidental y el pensamiento de pueblos originales tendrían, todos ellos, un notable paralelo con la propuesta de un sujeto ecológico. En este sentido, la idea de un sujeto ecológico integra las dimensiones materiales, espirituales y naturales para un re-ordenamiento de las prioridades que conducen sus ideales de vida.

En el horizonte de una crítica a la modernidad, específicamente al sujeto moderno, podemos traer a colación la tradición mística renana, la cual, entre otras cosas, niega al sujeto. Ello equivale al anatta budista, por cuanto el no-sujeto. Es común encontrar tradiciones que contengan nociones que sostengan una especie de muerte del sujeto, debido a que, en esa sublimación, la conciencia expandida y transformada se abre a otros seres, a otras realidades y normativas. Es ahí donde encontramos las raíces de nuestro sujeto ecológico que coloca a lo biológico y ambiental como eje de su preocupación y, solo a partir de ello, construye su identidad social; de ninguna forma pasando por encima de la naturaleza como si no fuera objeto de derecho.

De acuerdo a lo postulado por Enrique Leff (1994, 2006, 2008), en lo que refiere al actual problema ambiental, nos vemos en frente de una crisis civilizatoria, que abarca lo social, político, económico, lo relacionado a la razón, al pensamiento en general, al conocimiento y sus perspectivas; y lo que estamos jugándonos en el camino es nuestra condición de posibilidad para la vida misma, es decir, la crisis supone que nuestro desenvolvimiento en el mundo atenta contra el fundamento de nuestra existencia.

Las reflexiones de Leff, en la línea del problema medio-ambiental pueden darnos luces respecto a la sociedad que construimos, marcada actualmente por una estructura del dominio y cuya natural consecuencia es la marginación, la desigualdad y una justicia y bienestar social para limitados sectores. Ello nos debe invitar a cuestionar la esencia antropocéntrica del pensamiento que norma nuestros comportamientos morales en pequeña y gran escala. No puede significar nada hasta que involucre un cambio, no solo de conciencia, sino de un estilo de vida. Estas conclusiones son alcanzadas por diversos autores como Palmer y Aparicio (2017), Martinez y Porcelli (2017), Arroyave-Cabrera y Miller (2017), Rozzi (2012), Ferrer (2006), entre otros.

De forma paralela, podemos resaltar la importancia de una transición hacia una ecología profunda, al atender un artículo de Arroyave-Cabrera y Miller (2017) titulado "De la ecología de medios a la ecología profunda de medios", en el que se hace patente tal necesidad de romper con el paradigma antropocéntrico.

Se define a la ecología de medios como un movimiento que ha tenido impacto desde el siglo XX en las ciencias naturales y luego en las ciencias sociales. Supone un cambio fundamental en la comprensión inclusiva de nuestro ambiente y especialmente en el reparo del impacto negativo que han infligido tanto el capitalismo como el consumismo inscritos en una ideología depredadora, en donde el reconocimiento no llega a otros y mucho menos al ambiente de nuestro planeta.

La estructura de mercado que se fundamenta en tecnologías fósiles (aun cuando sabemos que no es la única ni la mejor), el incremento exponencial de desechos tecnológicos de los años recientes (computadoras desechadas, celulares, tablets, etc.) y la institución de un consumismo acrítico y 
malsano, son solo ciertas consecuencias que se pueden situar en forma paralela a la contaminación global de la atmósfera, de los océanos y terrenos; a la deforestación desmedida, y a un cambio climático de niveles extremos (Cfr. Arroyave-Cabrera y Miller, 2017).

Todo ello suma un cambio irreversible y determinante para nuestro planeta, y seríamos muy negligentes si dejáramos pasar que todos estos elementos son obra, fruto y consecuencia de prácticas sociales humanas con prioridades muy cuestionables, específicamente, una que invisibilice lo humano y lo natural.

\section{CONCLUSIONES}

En este artículo hemos buscado relacionar el problema del medio ambiente con sus causas. Al preguntarnos por la razón de una crisis ambiental tan extrema, nos topamos con nuestros usos culturales y económicos. No podemos dejar de observar de qué modo el consumismo de un capitalismo depredador aniquila el fundamento para la vida.

$\mathrm{Al}$ analizar la estructura social y conceptual que soporta tales prácticas, tendremos que dichos usos culturales se desprenden de una visión instrumental que cosifica al ser humano y a la naturaleza. Las consecuencias del pensamiento moderno suponen un abuso de la razón utilitarista en desmedro de reconocerles a ambos su condición de ser sujetos de derecho.

Si sopesamos el caso de América Latina, podremos considerar el acentuado carácter de dicha crisis, ya que las voces de los cronistas nos refieren desde hace mucho un problema que aparentemente no se puede superar. La ruptura del orden pre-occidental coincide con el inicio de una crisis sostenida que se manifiesta, por ejemplo, pero no exclusivamente, en la persecución inquisitorial de ideales tales como el del pachamamismo.

Alcanzando algunas de las raíces del problema ambiental de Latinoamérica, confrontamos los ideales modernos del colonialismo, cuyo triunfo supone la crisis ambiental, ante lo cual presentamos la idea de una ecología profunda que se le oponga. Los objetivos de tales posturas (de-colonialismo y ecología profunda) empatan en un horizonte complementario, pues, desde ambas críticas, se pone en cuestión el fundamento que rige los criterios sobre prioridades de la cultura y economía del mundo occidental.

Así, proponer el colonialismo como causa del problema ambiental en América Latina, nos pone en una postura equivalente a la de un sujeto ecológico capaz de transformar el núcleo de su ética en uno biocéntrico. En esa de-construcción del utilitarismo instrumental, podemos encontrar visos para confrontar los graves problemas pendientes del sexismo, clasismo, racismo y fanatismo religioso e ideológico que asedian a la humanidad globalmente. Ninguno de ellos tendrá sentido ni importancia si, como presupuesto, carecemos de un mundo que albergue a nuestras sociedades.

\section{BIBLIOGRAFÍA}

Arroyave-Cabrera, J. A. y Miller, T. (2017). De la ecología de medios a la ecología profunda de medios: esclarecerlametáfora y visibilizar su impacto medioambiental. Palabra Clave, 20(1), 239-268. DOI: 10.5294/pacla.2017.20.1.11 
Bautista, J.J. (2014). ¿Qué significa pensar desde América Latina? Hacia una racionalidad transmoderna y postoccidental. Madrid: Akal.

Betancourt, R. (2004). La interculturalidad como alternativa a la violencia. Filosofar para nuestro tiempo en clave intercultural. Aachen: Concordia. Recuperado de: https://campusvirtual.uarm.edu.pe/pluginfile.php/318033/mod_resource/content/0/L37.\%20Fo rnet\%20.\%20InterculturalidadAlternativalaviolencia.pdf

Beuchot, M. (1993). Elfundamento de los derechos humanos en Bartoloméde Las Casas. En: Areté5 (1-2): 4-13. Recuperado de:

https://campusvirtual.uarm.edu.pe/pluginfile.php/308096/mod_resource/content/0/L8\%20Beuc hot $\% 201993 \% 20 \mathrm{El} \% 20$ fundamento $\% 20 \mathrm{de} \% 20 \mathrm{los} \% 20 \mathrm{derechos} \% 20$ humanos $\% 20 \mathrm{en} \% 20$ Bartolo m\%C3\%A9\%20de\%20Las\%20Casas.pdf

Broswimmer, Franz J. (2005). Ecocidio. Breve historia de la extinción en masa de las especies. México: Océano.

Ferrer, Orlando (2006). Ecology for Whom? Deep Ecology and the Death of Anthropocentrism. En: Opción, Año 22, No 50 (2006): 181 -197 ISSN 1012 -1587

Gudynas, Eduardo (2017). Deep Ecologies in the Highland and Rainforests: Finding Naess in the Neotropics. En: Worldviews 21 (3): 262-275;2017. Recuperado de: http://gudynas.com/wpcontent/uploads/GudynasBiocentricAndesR17-1.pdf

Hidalgo-Capitán, Antonio y Cubillo-Guevara, Ana. (2017). Deconstruction and Genealogy of Latin American Good Living (Buen Vivir). The (Triune) Good Living and its Diverse Intellectual Wellsprings. En: International Development Policy, 9, 2017.

Horkheimer, Max (1969). Crítica de la razón instrumental. Buenos Aires: Sur.

Horkheimer, Max (2007) Zur kritik der instrumentallen Vernunft. Fischer Verlag: Frankfurt am Main.

Leff, Enrique (2008). Discursos Sustentables. México: Siglo XXI.

Leff, Enrique (2006). Aventuras de la Epistemología Ambiental. México: Siglo XXI.

Leff, Enrique (1986). Ecología y Capital. Racionalidad Ambiental, Democracia Participativa y Desarrollo Sustentable. México: Siglo XXI.

Martínez, Adriana y Porcelli, Adriana (2017). A new visión of the world: Deep ecology and its incipient reception in national and international law (first part). En: LEX N ${ }^{\circ} 20$ - AÑO XV - 2017

- II / ISSN 2313 - 1861

Mazzotti, J. A. (2018). El Inca Garcilaso y el calentamiento global: claves para una lectura contemporánea de los Comentarios reales. Philologia Hispalensis 32(2): 79-87.

Mayer-Tasch, Cornelius et al. (2019) Natur Denken, Eine Genealogie der ökologischen Idee. Springer VS

Mignolo, D. (2010). Desobediencia epistémica. Buenos Aires: del Signo.

Naess, Arne (1973). The Shallow and the Deep, Long-Range Ecology Movements: A Summary.

Inquiry, $\mathrm{N}^{\circ}$ 16. Traducido en: (2007) Revista Ambiente y Desarrollo, XXIII, $\mathrm{n}^{\circ}$ 1: 98-101.

Naess, Arne(1987). Self-Realization:AnEcologicalApproach to Being inthe World. The Trumpeter, $4, \mathrm{~N}^{\circ} 3$.

Naess, Arne (2001). [1989]. Ecology, community and lifestyle. Cambridge: Cambridge University Press.

Palmer, Ítaca y Aparicio, Pablo (2017). Ecocrítica e historicidad: releyendo a los clásicos, la naturaleza y la sociedad. En: Revista Interunivesitaria de Formación del Profesorado: Lecturas, ecología y educación: nuevas perspectivas para la formación del profesorado) No 90 (ISSN 0213-8646 | EISSN 2530-3791) 
Rossi, C. (2018). Palabras y piedras. La ciudad colonial en Garcilaso de la Vega y Guamán Poma de Ayala. CEHELIS-Revista del Centro de Letras Hispanoamericanas 35: 47-64.

Rozzi, Ricardo (2012). South American Environmental Philosophy: Ancestral Amerindian Roots and Emergent Academic Branches. En: Enviromental Ethics. Vol.34. Winter 2012. 